\title{
Antiepileptika og medfødte misdannelser
}

\begin{abstract}
BAKGRUNN Hos gravide kvinner med epilepsi kan bruk av antiepileptika gi økt risiko for fosterskader. For behandlende lege kan balansen mellom best mulig anfallskontroll og lavest mulige medikamentdoser være krevende. Hensikten med denne studien er å kartlegge forekomst og type misdannelser hos antiepileptikaeksponerte barn.
\end{abstract}

MATERIALE OG METODE Studien er ledd i en internasjonal kohortstudie. I Norge har vi prospektivt fulgt 813 graviditeter hos kvinner som bruker antiepileptika. Kvinnene blir fulgt med tre kontroller i løpet av graviditeten, og barna med to kontroller i løpet av første leveår.

RESULTATER Vi fant i alt 34 malformasjoner hos barna, hvorav 12 var kardiale. Det gir en malformasjonsrate på $4,5 \%$. Seks av misdannelsene ( $18 \%$ ) ble oppdaget prenatalt, 20 (59\%) ble rapportert rett etter fødselen og åtte (24\%) ble oppdaget i løpet av det første leveåret.

FORTOLKNING Vår studie viser at $95,5 \%$ av de inkluderte kvinnene som brukte antiepileptika i svangerskapet fødte friske barn. Vårt norske materiale er for lite til å bedømme den teratogene risikoen knyttet til de enkelte medikamentene.

Det er økt forekomst av medfødte misdannelser hos barn født av kvinner med epilepsi sammenliknet med barna til kvinner i den øvrige befolkningen (1). Det kan være flere mulige årsaker til dette, blant annet genetiske faktorer, epileptiske anfall under graviditeten og teratogene effekter av antiepileptika (1).

Flere tidligere studier av antiepileptikaassosierte føtopatier har hatt begrenset verdi fordi de har vært retrospektive og basert på små og selekterte pasientgrupper (2-4). Det er derfor nokså beskjeden kunnskap om den teratogene risikoen knyttet til enkeltpreparater. Særlig gjelder dette de nyeste antiepileptika, som for eksempel levetiracetam og eslikarbazepin. Fordi det i dag er rundt 25 antiepileptiske midler i bruk, er det helt nødvendig med store pasientmaterialer for å få mer informasjon om risikoen knyttet til det enkelte legemiddel.

Dette var bakgrunnen for at man i 1999 etablerte en internasjonal kohortstudie, EURAP (European Registry of Antiepileptic Drugs and Pregnancy) (5). Formålet var å kartlegge risikoen for større føtale misdannelser som følge av bruk av antiepileptika i svangerskapet samt finne ut hvilke legemidler som er tryggest under graviditet. Studien pågår fortsatt, og 42 land, også utenfor Europa, rapporterer nå til sentralregisteret i Milano. Mer enn 19000 graviditeter er hittil inkludert.

Norge kom med i studien i 2000, og de fleste norske nevrologiske avdelinger deltar. $\mathrm{Vi}$ har tidligere rapportert fra studien (6). Hensikten med denne artikkelen er å formidle resultater fra den norske delen, dvs. forekomst av og type misdannelser hos antiepileptikaeksponerte barn i Norge.

\section{Materiale og metode}

Ved inklusjon registreres demografiske data, epilepsitype, anfallstype og -frekvens, even- tuell komorbiditet, forekomst av medfødte misdannelser i familien, type antiepileptika og dose(r) i bruk og andre potensielle risikofaktorer. Gravide som bruker antiepileptika på konsepsjonstidspunktet, uansett indikasjon, kan delta i studien. Kvinnene må inkluderes før 16. svangerskapsuke, dvs. før utfallet av graviditeten er kjent. De følges poliklinisk med tre kontroller i løpet av svangerskapet. Etter fødselen blir barnet fulgt opp, første gang før det er tre måneder og siste gang etter 12 måneders alder.

Per mai 2013 var det fra Norge inkludert 1078 graviditeter. De nevrologiske avdelingene som har rekruttert flest, er vist i tabell 1. I Norge koordineres studien fra Spesialsykehuset for epilepsi (SSE) i Sandvika. Basert på journalopplysninger og intervju med kvinnen fyller nevrologen ut et spørreskjema for hver kontroll. Ved Spesialsykehuset for epilepsi blir svarene lagt inn $\mathrm{i}$ den norske delen av EURAP-databasen før de blir sendt videre til sentralregisteret $i$ Milano.

Av de 1078 graviditetene

er 143 foreløpig utelatt:

- 105 på grunn av fortsatt pågående graviditet

- 38 svangerskap er fullført, men data er foreløpig inkomplette

er 122 endelig utelatt:

- 54 på grunn av bytte av antiepileptikum i første trimester

- 44 fordi de ble inkludert etter 16. svangerskapsuke

- 24 er tapt underveis

Dersom det blir oppdaget et unormalt funn hos barnet, blir dette rapportert til Milano, der en sentral malformasjonskomité klassifiserer avviket. Komiteen er blindet for hvilket antiepileptikum kvinnen brukte under svanger-

\author{
Karl O. Nakken \\ karln@ous-hf.no \\ Kari Mette Lillestølen \\ Spesialsykehuset for epilepsi \\ Oslo universitetssykehus
}

Eylert Brodtkorb

Avdeling for nevrologi og klinisk nevrofysiologi

St. Olavs hospital

\section{Torleiv Svendsen}

Spesialsykehuset for epilepsi

Oslo universitetssykehus

og

Nevrologisk avdeling

Sykehuset Innlandet, Lillehammer

\section{Kathrine Johannessen Haggag}

Avdeling for voksenhabilitering

Oslo universitetssykehus, Ullevål

\section{Erik Taubøll}

Nevrologisk avdeling

Oslo universitetssykehus, Rikshospitalet

\section{HOVEDBUDSKAP}

Raten for medfødte misdannelser hos barn av mødre som bruker antiepilepika i svangerskapet er $4,5 \%$

Hyppigst er kardiale misdannelser (35\%)

Rundt en firedel av misdannelsene blir ikke fanget opp rett etter fødselen, men blir avdekket i løpet av barnets første leveår 
Tabell 1 De norske nevrologiske avdelinger som har rekruttert flest pasienter til EURAPstudien $(\mathrm{n}=813$ )

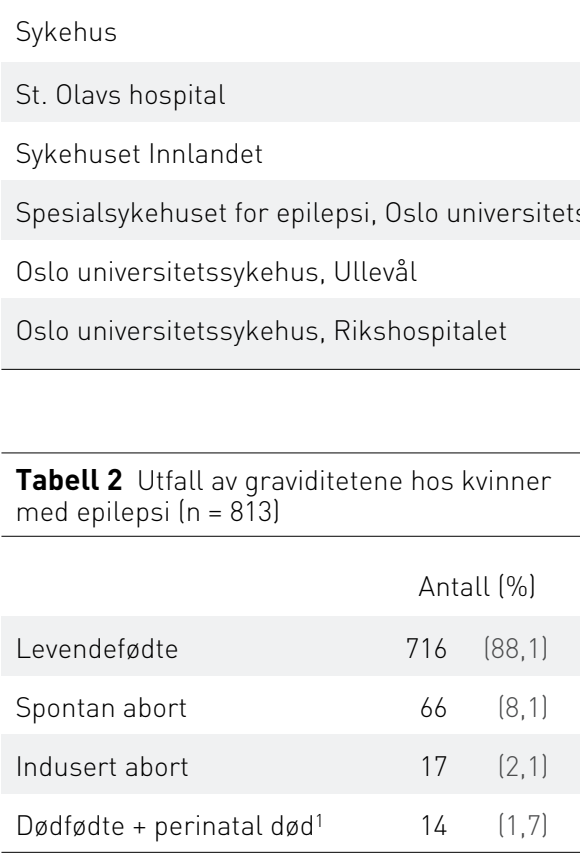

1 Død i løpet av 1. leveuke

Tabell 3 Misdannelser hos barn eksponert for antiepileptika i svangerskapet ( $n=34$ )

\begin{tabular}{lc}
\hline Misdannelser & Antall \\
Kardiale & 12 \\
Muskel- og skjelettsystemet & 5 \\
Ekstremiteter & 4 \\
Genitalia & 2 \\
Nervesystemet & 2 \\
Leppe-gane-spalte & 2 \\
Fordøyelsessystemet & 2 \\
Multiple misdannelser & 1 \\
Andre malformasjoner & 4 \\
Til sammen & 34 \\
\hline
\end{tabular}

skapet. En større misdannelse - eller «major congenital malformation» - er definert som et strukturelt avvik av kirurgisk, medisinsk, funksjonell eller kosmetisk betydning (7). Dette samsvarer med definisjonen som blir brukt i den populasjonbaserte EUROCATdatabasen (European Surveillance of Congenital Anomalies) (8).

Studieprotokollen er godkjent av etisk komité i Helseregion Sør (tidligere Helseregion 2) (S-01034).
Inkluderte graviditeter

$$
173
$$

134

126

108

\section{Resultater}

Studien omfatter 813 graviditeter. Tre av kvinnene brukte antiepileptika mot ikke-epileptiske tilstander. Utfallet av graviditetene er vist $\mathrm{i}$ tabell 2.

Hos 34 barn ble det funnet større misdannelser (major congenital malformation). Av disse resulterte to $\mathrm{i}$ indusert abort og to i neonatal død. Hos de to sistnevnte ble det funnet hydrocephalus og multiple misdannelser hos den ene og omfattende cerebrale misdannelser hos den andre. Seks av misdannelsene $(18 \%)$ ble oppdaget prenatalt, $20(59 \%)$ ble rapportert rett etter fødselen og åtte $(24 \%)$ ble oppdaget i løpet av barnets første leveår. Hyppigst var kardiale misdannelser (tab 3).

Det ble funnet fem barn med kromosomavvik. Disse regnes ikke blant misdannelsene.

Misdannelser hos 34 barn gir en total malformasjonsrate på 4,5\%. Hos kvinnene med monoterapi versus polyterapi var malformasjonsraten henholdsvis $4,1 \%$ og $6,4 \%$.

I 655 av graviditetene $(81 \%$ ) brukte kvinnen kun ett antiepileptikum (monoterapi). Mest brukt var lamotrigin $(\mathrm{n}=201)$, fulgt av karbamazepin $(n=150)$, levetiracetam $(n=78)$ og valproat $(n=71)$. Det ble brukt 51 ulike medikamentkombinasjoner. De hyppigste kombinasjonene var lamotrigin + levetirace$\operatorname{tam}(n=24)$, lamotrigin + valproat $(n=16)$ og lamotrigin + klonazepam $(\mathrm{n}=10)$.

Kvinnenes gjennomsnittsalder ved fødselen, barnas gjennomsnittlige fødselsvekt, andelen kvinner som var blitt gravide ved hjelp av in vitro-fertilisering og andelen utførte keisersnitt sammenliknet med data fra Medisinsk fødselsregister (9) er vist i tabell 4.

\section{Diskusjon}

Det viktigste funnet i denne studien er en malformasjonsrate på $4,5 \%$ hos barn av kvinner som bruker antiepileptika under graviditeten. Dette tilsvarer resultatet $\mathrm{i}$ en britisk studie (10), mens det i andre studier er funnet både høyere og lavere rate (11-14). Ifølge Medisinsk fødselsregister var malformasjonsraten hos barn født av alle norske kvinner i 2011 2,6\% (9).
Tallene er imidlertid ikke helt sammenliknbare, ettersom malformasjonsraten $\mathrm{i}$ registeret er basert på antall misdannelser som blir oppdaget før barnet utskrives fra fødeavdelingen, mens EURAP-registreringen først avsluttes når barnet er fylt ett år. Noen misdannelser fanges verken opp før eller rett etter fødselen. $24 \%$ av misdannelsene i vårt materiale ble først oppdaget i løpet barnets første leveår. En sammenlikning med Medisinsk fødselsregister blir dermed mer korrekt når man ekskluderer de åtte barna med misdannelser som ble oppdaget $i$ løpet av det første leveåret. Da blir malformasjonsraten hos de antiepileptikaeksponerte barna 3,4\%.

At rundt en firedel av misdannelsene blir oppdaget i løpet av det første leveåret, ble vist også i en australsk studie (15). Og at misdannelsesraten øker ved bruk av mer enn ett antiepileptikum i svangerskapet, er også funnet av andre $(1,10,11,16)$.

Vårt norske materiale er for lite for å kunne evaluere den teratogene risikoen knyttet til de enkelte preparatene. Imidlertid har foreløpige resultater fra EURAP-studien internasjonalt og fra andre tilsvarende registre vist at den største risikoen for misdannelser er knyttet til bruk av valproat $(7,10-14)$.

Per juni 2010 hadde man i EURAP samlet 5366 graviditeter der kvinnene hadde brukt monoterapi av enten lamotrigin, karbamazepin, valproat eller fenobarbital. Den samlede malformasjonraten blant disse var $6,0 \%$. For alle de fire medikamentene økte risikoen med økende doser. Lavest risiko hadde de som brukte under $300 \mathrm{mg}$ lamotrigin (2,0\%, $\mathrm{n}=836)$ og de som brukte under $400 \mathrm{mg}$ karbamazepin $(3,4 \%, n=148)$. Størst risiko for misdannelser hos barna hadde kvinner som brukte over $1500 \mathrm{mg}$ valproat $(24,2 \%$, $\mathrm{n}=99$ ) og kvinner som brukte over $150 \mathrm{mg}$ fenobarbital $(13,7 \%, \mathrm{n}=51)$. Risikoen var dessuten firedoblet dersom det forekom misdannelser i familien ( $\mathrm{OR}=4,4(95 \% \mathrm{KI}$ 2,06-9,23), $p=0,0001)(7)$.

Noe overraskende fant man at folatbruk også var forbundet med lett økt risiko $(\mathrm{OR}=1,4(95 \%$ KI 1,02-1,82), $\mathrm{p}=0,035)$. Dette kan trolig forklares med at det var en overvekt av kvinner med høy risiko for misdannelser som tok folat (confounding by indication).

Den økte risikoen ved bruk av polyterapi versus monoterapi er særlig tydelig dersom valproat er involvert $(10,16)$.

Selv om registerstudier har flere potensielle feilkilder og resultatene derfor må tolkes med varsomhet, er det likevel rimelig å forsikre dagens kvinner som må bruke antiepileptika i svangerskapet at sjansen for å få et friskt barn er på rundt $95 \%$.

Hos enkelte kvinner med lette epilepsier er det vår anbefaling at man bør vurdere å 
Tabell 4 Data fra den norske delen av EURAP-studien sammenliknet med data fra Medisinsk fødselsregister i 2011 (9)

\begin{tabular}{lrr} 
& $\begin{array}{r}\text { EURAP } \\
\text { (n=813) }\end{array}$ & $\begin{array}{r}\text { Medisinskfødselsregister } \\
\text { (n = 61 322) }\end{array}$ \\
Kvinnenes gjennomsnittsalder ved fødsel (år) & 29,8 & 27,7 \\
Barnas gjennomsnittlige fødselsvekt (g) & 3468 & 340 \\
Andel kvinner gravide ved hjelp av in vitro-fertilisering (\%) & 7,0 & 3,3 \\
Andel keisersnitt (\%) & 23,3 & 17,0 \\
\hline
\end{tabular}

trappe ned, helt eller delvis, antiepileptikabruken før en planlagt graviditet. Hvis dette ikke er forsvarlig, bør man tilstrebe lavest mulig dose og helst bruk av monoterapi. Samtidig er det viktig å huske at også anfall kan være skadelig for fosteret, særlig generelle krampeanfall.

Serumkonsentrasjonen av flere antiepileptika, for eksempel lamotrigin, levetiracetam og okskarbazepin, faller betydelig under en graviditet trass i uendret dose $(17,18)$. Særlig hos disse kvinnene er det viktig å følge serumkonsentrasjonen og eventuelt justere dosene dersom fallet overstiger $25-30 \%$. Vi viser for øvrig til de norske retningslinjene for behandling av kvinner med epilepsi (19).

Hos kvinnene med epilepsi ble det foretatt flere keisersnitt enn det som er landsgjennomsnittet. Dette er trolig relatert til at noen frykter anfall i tilslutning til fødselen, og disse fødslene blir ofte ansett som risikofødsler. De aller fleste kvinner med epilepsi bør kunne føde vaginalt (20).

Det har vært diskutert om barn eksponert for antiepileptika i svangerskapet har en lett økt risiko for redusert intrauterin vekst (21). $\mathrm{Vi}$ fant at barna i vårt materiale hadde en fødselsvekt som var tilnærmet lik fødselsvekten til barn registrert i Medisinsk fødselsregister (9). At kvinnene i vårt materiale i gjennomsnitt var vel to år eldre enn kvinnene i Medisinsk fødselsregister, kan muligens ha gitt en lett økt risiko for misdannelser.

Kvinner med epilepsi har lavere fødselsrate enn kvinner uten epilepsi $(22,23)$. Det er sannsynligvis sammensatte grunner til dette. Både epilepsitypen, anfallene (særlig temporallappsanfall), antiepileptika, årsaken til epilepsien og psykososiale faktorer kan bidra (22-24). Blant kvinnene $\mathrm{i}$ vårt materiale var det et relativt høyt antall svangerskap etter assistert befruktning, noe som kan indikere nedsatt fertilitet.

Aborttallene er vanskelige å vurdere, spesielt spontanabortene, ettersom det her antas å være store mørketall. I en studie fra India fant man at risikoen for spontanabort hos kvinner som brukte antiepileptika var høyere
(4\%) enn hos kontrollkvinnene (2\%), og den var høyere ved bruk av valproat $(8 \%)$ enn ved bruk av andre antiepileptika $(1-6 \%)(25)$.

Andelen dødfødte barn og barn som døde perinatalt $(n=14)$ var høyere i vårt materiale enn i befolkningen for øvrig $(1,7 \%$ versus $0,39 \%$ ) (4). Dette er i tråd med resultater fra tidligere studier (26).

\section{Konklusjon}

Vi fant at hos barn født av kvinner som brukte antiepileptika i svangerskapet, var forekomsten av misdannelser som ble oppdaget straks etter fødselen $3,4 \%$, mens den 12 måneder etter fødselen var 4,5\%. Hyppigst var kardiale misdannelser. Vår anbefaling er at man hvis mulig bør unngå bruk av valproat hos disse kvinnene, og man bør tilstrebe bruk av monoterapi - og i laveste effektive dose (21).

\section{Karl 0. Nakken (f. 1945)}

er spesialist i nevrologi med spesialkompetanse innen epilepsisykdommer. Han er medisinsk fagsjef ved Avdeling for kompleks epilepsi ved Oslo universitetssykehus og nasjonal koordinator for EURAP-studien i Norge.

Forfatter har fylt ut ICMJE-skjemaet og oppgir ingen interessekonflikter.

\section{Kari Mette Lillestølen (f. 1954)}

har vært studiesykepleier ved Avdeling for kompleks epilepsi og er studiesykepleier og forskningssekretær i Forskningsenheten for nevrofagene ved Oslo universitetssykehus. Hun har hatt en sentral rolle i EURAP-studien i Norge fra starten i 2000.

Forfatter har fylt ut ICMJE-skjemaet og oppgir ingen interessekonflikter.

\section{Eylert Brodtkorb (f. 1948)}

er spesialist i nevrologi, overlege og professor ved Institutt for nevromedisin, Norges teknisknaturvitenskapelige universitet.

Forfatter har fylt ut ICMJE-skjemaet og oppgir følgende interessekonflikter: Han har mottatt reisestøtte/foredragshonorar fra UCB Pharma, Eisai og GlaxoSmithKline.

\section{Torleiv Svendsen (f. 1962)}

er spesialist i nevrologi og seksjonsoverlege ved Seksjon for voksenepilepsi ved SSE.

Forfatter har fylt ut ICMJE-skjemaet og oppgir ingen interessekonflikter.

\section{Kathrine Johannessen Haggag (f. 1958)} er spesialist i nevrologi og seksjonsoverlege. Forfatter har fylt ut ICMJE-skjemaet og oppgir ingen interessekonflikter.

\section{Erik Taubøll (f. 1957)}

er spesialist i nevrologi, med spesialkompetanse innen epilepsi. Han er seksjonsoverlege og professor og leder avdelingens gruppe for epilepsiforskning.

Forfatter har fylt ut ICMJE-skjemaet og oppgir ingen interessekonflikter.

\section{Litteratur}

1. Meador K, Reynolds MW, Crean S et al. Pregnancy outcomes in women with epilepsy: a systematic review and meta-analysis of published pregnancy registries and cohorts. Epilepsy Res 2008; 81: $1-13$.

2. Samrén EB, van Duijn CM, Christiaens GC et al. Antiepileptic drug regimens and major congenital abnormalities in the offspring. Ann Neurol 1999; 46: $739-46$

3. Kaneko S, Battino D, Andermann E et al. Congenital malformations due to antiepileptic drugs. Epilepsy Res 1999; 33: 145-58.

4. Holmes LB, Harvey EA, Coull BA et al. The teratogenicity of anticonvulsant drugs. N Engl J Med 2001; 344: 1132-8.

5. EURAP Study Group. Seizure control and treatment in pregnancy: observations from the EURAP epilepsy pregnancy registry. Neurology 2006; 66: 354-60.

6. Nakken KO, Lillestølen KM, Taubøll E et al. Epilepsi og svangerskap - medikamentbruk, anfallskontroll og komplikasjoner. Tidsskr Nor Lægeforen 2006; 126: 2507-10.

7. Tomson T, Battino D, Bonizzoni E et al. Dosedependent risk of malformations with antiepileptic drugs: an analysis of data from the EURAP epilepsy and pregnancy registry. Lancet Neurol 2011 10: 609-17.

8. EUROCAT. www.eurocat-network.eu/ (21.3.2014).

9. Årstabeller for Medisinsk fødselsregister 2011. Fødsler i Norge. Oslo: Divisjon for epidemiologi Folkehelseinstituttet, 2013

10. Morrow J, Russell A, Guthrie E et al. Malformation risks of antiepileptic drugs in pregnancy: a prospective study from the UK Epilepsy and Pregnancy Register. J Neurol Neurosurg Psychiatry 2006; 77: 193-8.

11. Tomson T. Battino D. Teratogenic effects of antiepileptic drugs. Lancet Neurol 2012; 11: 803-13.

12. Hernández-Díaz S, Smith CR, Shen A et al. Comparative safety of antiepileptic drugs during pregnancy. Neurology 2012; 78: 1692-9.

13. Campbell E, Kennedy F, Russell A et al. Malformation risks of antiepileptic drug monotherapies in pregnancy: updated results from the UK and Ireland Epilepsy and Pregnancy Registers. J Neurol Neurosurg Psychiatry 2014. E-publisert 3.2

14. Vajda FJ, Graham J, Roten A et al. Teratogenicity of the newer antiepileptic drugs-the Australian experience. J Clin Neurosci 2012; 19: 57-9.

15. Vajda FJ, Graham J, Hitchcock AA et al. Foetal malformations after exposure to antiepileptic drugs in utero assessed at birth and 12 months later: observations from the Australian pregnancy register. Acta Neurol Scand 2011; 124: 9-12. 
16. Vajda FJ, Hitchcock AA, Graham J et al. The teratogenic risk of antiepileptic drug polytherapy. Epilepsia 2010; 51: 805-10.

17. Reimers A, Brodtkorb E. Second-generation antiepileptic drugs and pregnancy: a guide for clinicians. Expert Rev Neurother 2012; 12: 707-17.

18. Reisinger TL, Newman M, Loring DW et al. Antiepileptic drug clearance and seizure frequency during pregnancy in women with epilepsy. Epilepsy Behav 2013; 29: 13-8.

19. Røste LS. Retningslinjer for behandling av kvinner med epilepsi. Konsensusrapport. Oslo: Den norske legeforening, 2011

20. Harden CL, Hopp J, Ting TY et al. Management issues for women with epilepsy-Focus on pregnancy (an evidence-based review): I. Obstetrical complications and change in seizure frequency: Report of the Quality Standards Subcommittee and Therapeutics and Technology Assessment Subcommittee of the American Academy of Neurology and the American Epilepsy Society. Epilepsia 2009 50: $1229-36$.

21. Harden CL, Meador KJ, Pennell PB et al. Management issues for women with epilepsy-Focus on pregnancy (an evidence-based review): II. Teratogenesis and perinatal outcomes: Report of the Quality Standards Subcommittee and Therapeutics and Technology Subcommittee of the American Academy of Neurology and the American Epilepsy Society. Epilepsia 2009; 50: 1237-46.

22. Luef $G$. Female issues in epilepsy: a critical review. Epilepsy Behav 2009; 15: 78-82.
23. Verrotti A, D’Egidio C, Mohn A et al. Antiepileptic drugs, sex hormones, and PCOS. Epilepsia 2011; 52: 199-211

24. Kariuki JG, Joshi MD, Adam AM et al. Fertility rate of epileptic women at Kenyatta National Hospital. East Afr Med J 2008; 85: 341-6.

25. Thomas SV, Sindhu K, Ajaykumar B et al. Maternal and obstetric outcome of women with epilepsy. Seizure 2009; 18: 163-6

26. Yerby MS, Kaplan P, Tran T. Risks and management of pregnancy in women with epilepsy. Cleve Clin J Med 2004; 71 (suppl 2): S25-37.

Mottatt 18.10. 2013, første revisjon innsendt 14.2 . 2014, godkjent 21.3. 2014. Redaktør: Tor Rosness. 